\title{
Pharmacy workers in Kenya need training and support on medical abortion information and referrals to prevent unsafe service provision
}

Jesse Njunguru

A. Finnie

Katharine Footman

Wilson Liambila

Population Council

Kate Reiss

Follow this and additional works at: https://knowledgecommons.popcouncil.org/departments_sbsr-rh

Part of the Demography, Population, and Ecology Commons, Family, Life Course, and Society Commons, International Public Health Commons, and the Women's Health Commons How does access to this work benefit you? Let us know!

\section{Recommended Citation}

Njunguru, Jesse, A. Finnie, Katharine Footman, Wilson Liambila, and Kate Reiss. 2016. "Pharmacy workers in Kenya need training and support on medical abortion information and referrals to prevent unsafe service provision," STEP UP Policy Brief. London: Marie Stopes International. 


\section{POLICY BRIEF}

MARCH 2016
STEP UP generates policy-relevant research to promote an evidencebased approach for improving access to family planning and safe abortion.

We work in Bangladesh northern India, Ghana, Kenya, and Senegal.

Population Council Coordinating Partner

African Population and Health Research Center

London School of Hygiene and Tropical Medicine

Marie Stopes International

Partners in Population and Development

Funded by

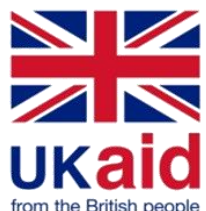

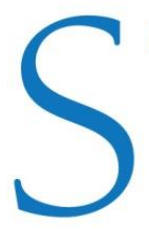
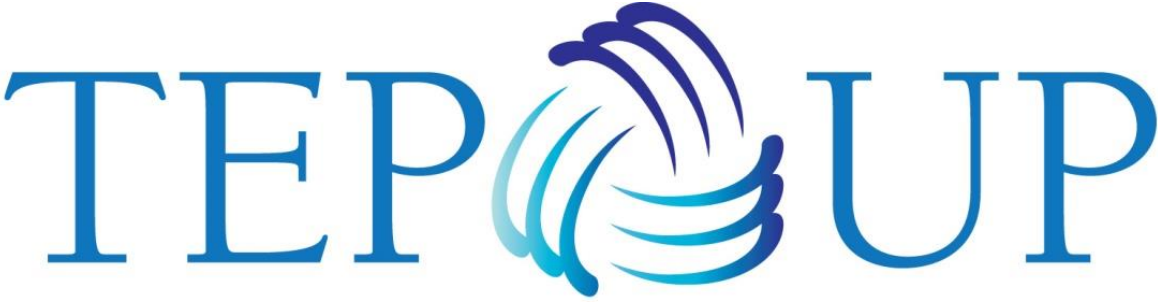

STRENGTHENING EVIDENCE FOR PROGRAMMING ON UNINTENDED PREGNANCY

\section{INTRODUCTION}

Unsafe abortion accounts for close to $35 \%$ of maternal deaths in Kenya, compared to a global average of $13 \%$. There are approximately 465,000 induced abortions in Kenya each year and a large proportion of these are clandestine and unsafe. In 2012 120,000 women were hospitalised for complications arising from unsafe procedures, at an estimated cost to the Kenyan government of 65 USD per patient.

Medical abortion (MA), using the WHO recommended regimen of combined mifepristone and misoprostol, is a safe and cost effective alternative to surgical abortion.

In Kenya, pharmacies often act as a point of information for women seeking abortion services, as they offer anonymity, easy access, and affordable services. Within Kenya's current legal framework, pharmacy workers can inform abortion clients of available methods, offer referrals, and sell MA drugs when presented with a valid prescription. Pharmacies therefore play a front line role in the provision of MA drugs and information.

\section{ABOUT THIS STUDY}

Despite the centrality of pharmacists in the provision of abortion services, little is known about their MA knowledge, attitudes or practices. This study therefore set out to bridge this gap in the evidence.

In 2013 we interviewed 235 pharmacy workers in Nairobi, Mombasa and Kisumu about the medical abortion services they provide. In addition, women pretending to seek abortion services without a prescription visited 138 pharmacies as mystery shoppers, and documented the counselling and medications they were offered.

\section{RECOMMENDATIONS}

For medical colleges, training institutions \& professional associations:

- Pharmacy workers should receive training on MA regimens,

counselling, and legal status to ensure correct information provision and to encourage referrals to safe sources of care.

- Medical training college curriculums for medicine, nursing and pharmacy should be updated to include MA regimens, information provision, and the legal framework.

- Professional associations such as the Pharmaceutical Society of Kenya (PSK) , and the Kenya Pharmaceutical Association (KPA) should support pharmacists to provide correct information on MA.

\section{For the Ministry of Health:}

- National guidelines on safe abortion should acknowledge the role of pharmacy workers in providing information and referrals for MA

- Referral linkages should be strengthened through incentives for MA or post-abortion care referrals to trained clinicians.

- Sensitivity training on MA practices should be provided to pharmacy workers and health care providers in the same setting to dispel mistrust. 


\section{RESULTS}

\section{Pharmacy workers are providing women with MA drugs and information}

- $62 \%$ of pharmacy workers provided information on abortion methods to mystery shoppers, and $28 \%$ offered MA drugs.

- Demand for abortion services is high: pharmacies that provide MA information and drugs reported an average of 12 women seeking abortion services per month. Among pharmacies that do not provide MA information and drugs, most (74\%) said that their clients ask for these services.

\section{However, pharmacy workers do not know correct MA regimens, side effects, or the legal status of MA}

- Only $9 \%$ of pharmacy workers could state the correct WHO approved mifepristone-misoprostol MA regimen. Knowledge of the misoprostol-only regimen, which is a less effective method of MA, was higher $(19 \%)$.

- Among those who did know the correct regimen, many were unable to name side effects or potential complications.

- Pharmacy workers also have limited knowledge of the laws governing MA provision; only $30 \%$ knew that misoprostol was registered as an abortifacient.

\section{Pharmacy workers want more training on MA}

- Only $14 \%$ of pharmacy workers have received training on abortion services, and among those, only half $(53 \%)$ have been trained on medical methods.

- Many respondents (46\%) expressed desire for training on abortion services. The most commonly requested training topics were:

- MA methods

- Recognition and management of abortion complications

- Abortion policy and law

\footnotetext{
Suggested citation:

Njunguru, J., Finnie, A., Footman, K., Liambila, W., Reiss, K. 2016. "Pharmacy workers in Kenya need training and support on medical abortion information and referrals to prevent unsafe service provision." STEP UP Policy Brief, March 2016. London: Marie Stopes International.
}

\section{Only $9 \%$ of pharmacy workers could state the WHO-approved regimen for medical abortion.}

\section{DISCUSSION}

Pharmacy workers in Kenya are important frontline providers of MA information and drugs (when presented with a prescription). They face high demand for MA services from the community, and many are providing women with MA information and drugs. However, pharmacy workers have little knowledge of correct MA regimens, side effects, complications, or the legality of MA, meaning that they cannot provide adequate information to clients. This suggests that potentially, pharmacists are inadvertently putting their clients' health at risk by providing incorrect or inadequate information. Their skills must be reinforced so that Kenya can take advantage of their important role at the forefront of community health.

Comprehensive training for pharmacy workers could improve the quality of MA provision and referrals, and help pharmacy workers identify opportunities to simultaneously provide clients with information on contraception and STI prevention. Such efforts would be in line with current government policies to reduce the public health burden caused by the prevalence of unsafe abortion and HIV, and within the boundaries of the current legal framework.

\section{SUGGESTED READINGS}

1. Reiss K, Footman K, Akora V, Liambila W, Ngo T. 2016. Pharmacy workers' knowledge and provision of medication for termination of pregnancy in Kenya. Journal of Family Planning and Reproductive Health Care.

\section{Mumah J, Kabiru CW, Mukiira C, et al. 2014.} Unintended Pregnancies in Kenya : A Country Profile. Nairobi: African Population and Health Research Centre.

3. African Population and Health Research Centre. Women's Lives Matter, Preventing Unsafe Abortion in Kenya. Key Findings of a National Study: Incidence and Complications of Unsafe Abortion in Kenya. 2013. APHRC Policy Brief Issue no. 1, August 2013.

4. Liambila W, Obare F, Ikiugu E, Akora V, et al. 2015. Availability, use and quality of care for medical abortion services in private facilities in Kenya. STEP UP Research Report. Nairobi: Population Council. 